\title{
La independencia del juez frente a la inconstitucionalidad de precedentes vinculantes establecidos por el Tribunal Constitucional peruano ${ }^{1}$
}

\author{
Judicial Independence against Unconstitutional Precedents Established by \\ the Constitutional Court of Peru
}

Daniel RAA-ORTIZ ${ }^{2}$

Mariana ISERN 3

\begin{abstract}
Resumen: Esta investigación expone las condiciones por las cuales el juez peruano pueda inaplicar un precedente emitido por el Tribunal Constitucional en ejercicio de su independencia jurisdiccional. La jurisprudencia internacional y nacional consultadas y emitidas por los órganos de control constitucional competentes arroja como resultado que el juez puede inaplicar un precedente bajo ciertos parámetros que deben estar contenidos en su decisión.
\end{abstract}

Palabras clave: Derecho procesal constitucional, precedente, independencia judicial, Tribunal Constitucional

Abstract: In this study the authors set forth the conditions under which Peruvian judges may disregard binding precedents decided by the Constitutional Court, in the exercise of their judicial independence. After reviewing international and domestic jurisprudence established

\footnotetext{
${ }^{1}$ La presente investigación es producto de la Tesis (titulada igual) de Maestría en Derecho Procesal por la Facultad de Derecho de la Universidad Nacional de Rosario (Argentina), defendida y aprobada el 25 de septiembre del 2017.

${ }^{2}$ Abogado en ejercicio. Docente en la Universidad Nacional Mayor de San Marcos (Perú). Magíster en Derecho Procesal por la Facultad de Derecho de la Universidad Nacional de Rosario (Argentina). Doctorando en Derecho en la Universidad Nacional de Rosario (Argentina). Correo electrónico: danielrraa@gmail.com

${ }^{3}$ Doctora en Derecho, Universidad Nacional de Rosario (2010), Profesora Adjunta de Filosofía del Derecho, en la Facultad de Derecho-UNR. Docente de la Facultad de Derecho-UNR: Doctorado en Derecho (Epistemología y Taller de Tesis), Maestría en Derecho Privado (Epistemología, Metodología de la Investigación y Taller de tesis) y de la Facultad de Ciencias Agrarias-UNR: Doctorado en Ciencias Agrarias-Maestría en Recursos Naturales-Maestría en Genética (Epistemología). Correo electrónico: marianaisern@yahoo.com.ar
} 
by competent constitutional review bodies, the authors argue that judges may disregard binding precedents if their decision includes specific parameters.

Keywords: Constitutional procedural law, precedents, judicial independence, Constitutional Court

\section{Introducción}

Esta investigación se enmarca en el conflicto en el derecho procesal constitucional peruano de dos instituciones: la técnica de precedentes constitucionales vinculantes y la garantíaderecho de la independencia judicial. El problema ha sido resuelto, casi en su mayoría, a nivel legal debido a la existencia de una norma jurídica expresa (el artículo VII del Título Preliminar del Código Procesal Constitucional peruano) que regula una cláusula de prohibición de inaplicación de precedentes por parte de los jueces ordinarios.

Sin embargo, la regulación legal no otorga una solución adecuada al problema, sino que es el origen del mismo, lo cual genera adicionalmente, a nivel macro, enfrentamiento entre el Tribunal Constitucional peruano y el Poder Judicial (o denominado conflicto de Cortes), que tienen a cargo, por mandato constitucional, la protección de derechos fundamentales de las personas y de la propia Constitución.

Por ello, en esta investigación se verifica que la independencia del juez peruano se afecta cuando está obligado o limitado a aplicar obligatoriamente un precedente vinculante, siempre y cuando vulnere la Constitución. Como consecuencia de lo expuesto, se comprobará que el juez peruano, en ejercicio de su autonomía e independencia, puede inaplicar un precedente vinculante bajo determinados parámetros.

\section{El precedente vinculante}

En primer término, es indispensable definir las características, tipos y naturaleza de la figura del precedente vinculante, los cuales desarrollaremos a continuación: 


\subsection{LOS ALCANCES DEL TÉRMINO PRECEDENTE}

El precedente es aquella parte de la sentencia que contiene la razón jurídica o ratio decidendi para resolver la controversia ${ }^{4}$, que incorpora elementos fácticos para que sirvan de parámetro no solo al juez al analizar si aplica o no el precedente, sino también a los ciudadanos para conocer de antemano cuáles son aquellos supuestos de hecho en los cuales se aplica una determinada norma jurídica.

Por otro lado, el precedente es también considerado una técnica de argumentación jurídica que consiste que el juez pueda analizar y decidir por qué en un caso específico tiene que aplicar el mismo, motivando su decisión 5 .

\subsection{TIPOLOGÍAS DE LOS PRECEDENTES: ENTRE EL DEBER JUDICIAL DE RESPETO Y LA JERARQUÍAJUDICIAL}

Un primer criterio clasificatorio parte de la premisa del deber judicial de respeto por los precedentes emitidos por el órgano jurisdiccional, lo cual tiene incidencia directa en la eficacia del precedente no solo frente a los jueces, sino también a las partes. Por tanto, la obligatoriedad del precedente puede ser absoluta o relativa ${ }^{6}$.

Otro criterio clasificatorio se sustenta en función a la jerarquía funcional de los jueces que emiten y aplican precedentes ${ }^{7}$, pudiendo tener tres tipos: verticales, horizontales y el autoprecedente.

El precedente vertical es aquel que ha sido emitido por los órganos judiciales superiores. Por otro lado, el precedente es horizontal cuando los dos órganos judiciales son de la misma jerarquía funcional en la organización judicial. Finalmente, el autoprecedente es el acatamiento por el mismo órgano judicial de sus propios fallos, manteniendo la uniformidad en sus decisiones ${ }^{8}$.

${ }^{4}$ Graziadei (2015), p. 208, Marinoni (2013), p. 123, Igartua (2010), pp. 27-28.

${ }^{5}$ Castillo (2008), p. 22, Lozano (2011), p. 178.

${ }^{6}$ Marinoni (2013), pp. 124-125.

${ }^{7}$ Igartua (2010), pp. 28-29, Castillo (2008), pp. 34-39.

${ }^{8}$ Castillo (2008), p. 37. 


\subsection{LA FUERZA VINCULANTE DEL PRECEDENTE}

Considerada como su principal característica, la fuerza vinculante consiste en el carácter de obligatoriedad del precedente frente a terceros, es decir su eficacia erga omnes frente a otros operadores y sujetos de derecho, de manera similar que una norma jurídica9 .

Sin embargo, en el sistema jurídico romano-germánico, la obligatoriedad del precedente puede ser restringida, debido que está supeditada a lo que refiera el ordenamiento jurídico (sea la Constitución o una ley) ${ }^{10}$.

En el caso que el ordenamiento jurídico no regule sobre la obligatoriedad del precedente o su vinculatoriedad, este tiene mismo valor que cualquier regla jurisprudencial con eficacia solo entre los sujetos del proceso en el que se emitió.

\section{El precedente vinculante en el código procesal constitucional peruano}

Habiendo definido aspectos generales del precedente, a continuación, se desarrollará la forma en la que se ha regulado por el ordenamiento procesal constitucional peruano:

\subsection{EL PRECEDENTE VINCULANTE POR EL TRIBUNAL CONSTITUCIONAL PERUANO}

El artículo VII del Título Preliminar del Código Procesal Constitucional peruano — Ley $\mathrm{N}^{\circ}$ 28237- incorporó en el ordenamiento jurídico peruano la técnica del precedente, señalando lo siguiente:

\footnotetext{
Las sentencias del Tribunal Constitucional que adquieren la autoridad de cosa juzgada constituyen precedente vinculante cuando así lo exprese la sentencia, precisando el extremo de su efecto normativo. Cuando el Tribunal Constitucional resuelva apartándose del precedente, debe expresar los fundamentos de hecho y de derecho que sustentan la sentencia y las razones por las cuales se aparta del precedente.
}

El Tribunal Constitucional Peruano ha definido el precedente ${ }^{11}$ como una regla jurídica para la solución de casos similares futuros, con carácter obligatorio (con efecto similar a una ley) para todos los poderes públicos y cualquier sujeto procesal.

\footnotetext{
${ }^{9}$ Bernal (2006), pp. 26-27.

${ }^{10}$ Núñez (2012), p. 16-17, Zúñiga (2006), p. 158.

${ }^{11}$ Tribunal Constitucional Peruano, Expediente 0024-2003-AI/TC, 10 de octubre del 2005.
} 
Asimismo, el precedente vinculante solo puede ser emitido por el Tribunal Constitucional Peruano en su calidad de órgano constitucional que resuelve de manera definitiva aquellos conflictos relacionados a la defensa de derechos fundamentales o la vigencia de la norma constitucional ${ }^{12}$.

El precedente vinculante constitucional constituye una herramienta que permite la unificación de interpretación de aspectos sustantivos o procesales de protección de derechos constitucionales o de las competencias de órganos constitucionales, siendo relevante determinar los alcances de su aplicación por los operadores judiciales ${ }^{13}$.

\subsection{LA OBLIGATORIEDAD DEL PRECEDENTE Y MODIFICACIÓN DEL PRECEDENTE (PROSPECTIVE OVERRULING)}

Es necesario destacar que el artículo VII del Código Procesal Constitucional peruano destaca la obligatoriedad del precedente de manera absoluta sea por argumentos de índole formal (por razones de seguridad jurídica o por ser emitido por el Tribunal Constitucional) o sustantivo (razonabilidad del precedente) ${ }^{14}$, siendo el propio Tribunal Constitucional quien puede decidir dejar sin efecto o apartarse del precedente vinculante, también denominado prospective overruling ${ }^{15}$.

Finalmente, el cambio de criterio jurisprudencial o prospective overruling es la variación del precedente vinculante porque habiendo sido dado en una situación determinada, es necesario su modificación, adecuándola a nuevos estándares establecidos por el Tribunal Constitucional.

\section{La independencia judicial}

En el presente punto se analizará el contenido y alcances de la garantía-derecho de la independencia judicial, conforme a lo siguiente:

\footnotetext{
12 Velezmoro (2010), p. 117-133.

13 Vinatea (2012), p. 17.

${ }^{14}$ Indacochea (2010), p. 167.

${ }^{15}$ Hakansson-Nieto (2009), p. 03.
} 


\subsection{LA INDEPENDENCIA JUDICIAL EN EL GARANTISMO PROCESAL}

El enfoque que el derecho procesal ha efectuado respecto a la afectación de la independencia judicial se ha restringido básicamente con relación a los sujetos y el objeto del proceso, entendiéndolo en algunas ocasiones — de manera errónea- como imparcialidad.

En ese sentido, la posición a adoptarse es la del derecho procesal garantista que entiende que el juez debe ser independiente de los demás poderes instituidos ${ }^{16}$. El profesor Adolfo Alvarado Velloso sostiene que la independencia forma parte del contenido del principio de imparcialidad del juzgador, juntamente con el concepto de impartialidad e imparcialidad en sentido estricto ${ }^{17}$, porque el juzgador debe actuar sin subordinación jerárquica respecto a las dos partes.

Consideramos que la independencia del juez no solo debe ser con respecto a las partes y a los poderes del Estado, sino también a aquellos órganos creados por las Constituciones y que le otorgan determinadas cuotas de poder con competencias específicas.

En conclusión, la independencia judicial se presenta como premisa inexcusable del Estado Constitucional de derecho y como garantía de una justicia no subordinada a razones de Estado o a intereses políticos contingentes.

\subsection{LA INDEPENDENCIA JUDICIAL COMO GARANTÍA CONSTITUCIONAL NO SOLO DE LAS PARTES SINO DEL JUEZ}

La independencia judicial debe también ser entendida como una garantía del juez frente a la solución de la controversia. Si el juez no es independiente, las partes no tienen seguridad que el proceso se resolverá conforme a lo actuado.

La independencia judicial como garantía del juez no debe ser entendida como neutralidad absoluta, debido que este es un ser humano con convicciones personales y sociales. Sin embargo, lo que se le exige al juez es que estas no sean predominantes o influyan en la decisión del caso que vaya a resolver, ateniéndose únicamente a lo actuado en el proceso.

${ }^{16}$ Superti (2006), pp. 325-326.

${ }^{17}$ Alvarado (2011), p. 201. 
Por estas razones la independencia judicial obliga a un esfuerzo mental del juez que debe anteponer cualquier tipo de influencia de terceros sea dentro de su misma organización judicial, de las partes o de terceros ajenos al proceso (particulares o del propio Estado) en su criterio jurídico específico en la decisión del caso.

Finalmente, la independencia judicial no significa acatamiento acrítico de las decisiones de otros órganos judiciales o respeto irrestricto a una decisión judicial. No pretendemos sostener que el juez tiene, en el ejercicio de su independencia, una libertad absoluta, sino que tiene la obligación de sustentar su posición respecto a la decisión de un caso, más cuando puede ser contraria a una decisión institucional o superior.

\title{
5. La independencia judicial en el ordenamiento jurídico peruano: la autonomía del juez y la defensa del estado de derecho
}

La Constitución Política del Perú de 1993 consagra la independencia en el ejercicio de la función jurisdiccional en el inciso 2) del artículo 139oㅡㄹ la cual ha sido interpretada por el Tribunal Constitucional al señalar que:

\begin{abstract}
La independencia judicial exige que el legislador adopte las medidas necesarias y oportunas a fin de que el órgano y sus miembros administren justicia con estricta sujeción al Derecho y a la Constitución, sin que sea posible la injerencia de extraños (otros poderes públicos o sociales, e incluso órganos del mismo ente judicial) a la hora de delimitar e interpretar el sector del ordenamiento jurídico que ha de aplicarse en cada caso (...) (Fundamento jurídico 28 de la Sentencia del Tribunal Constitucional recaída en el Expediente № 0023-2003-AI/TC).
\end{abstract}

Lo expuesto se advierte con mayor claridad en el segundo párrafo del artículo 146으 de la Constitución Política del Estado peruano al señalar que el Estado garantiza a los juzgadores: a) su independencia debido que solo están sometidos a la Constitución y a la ley; b) la inamovilidad en sus cargos porque no pueden ser trasladados sin su consentimiento; c) su permanencia en el servicio mientras conserven conducta e idoneidad propias de su función; y d) una remuneración que les asegure un nivel de vida digno de su misión y jerarquía.

Adicionalmente, el Tribunal Constitucional peruano ha señalado que la independencia judicial tiene un contenido interno y un contenido externo ${ }^{18}$. La independencia externa está relacionada con la relación que debe tener el juez con cualquier tipo de poder fuera de la organización judicial y la independencia interna está referida a la relación del juez con

18 Tribunal Constitucional del Perú, Expediente 0004-2006-AI/TC, 29 de marzo del 2006. 
cualquier tipo de poder dentro de la misma organización. La independencia se afecta cuando el juez recibe influencias de terceros ajenos al proceso sea fuera o dentro de la organización judicial $^{19}$.

De la interpretación realizada por el Tribunal Constitucional se advierte que el contenido de la independencia judicial interna es absoluto. Es decir, ninguna autoridad dentro de la misma estructura judicial puede influenciar a un juez para resolver una controversia en determinado sentido; sin embargo, la independencia judicial no se aplica cuando dicha "influencia" es emitida en el contexto de un medio impugnatorio dentro del proceso que el juez conoce $^{20}$.

Se advierte que la independencia interna es una independencia funcional del juez dentro de la institución judicial. Es decir, se proscribe cualquier intromisión de un juez en la decisión de otro en un proceso, pudiendo ser la misma horizontal y vertical ${ }^{21}$.

No obstante, la interpretación del Tribunal Constitucional Peruano debe tenerse en cuenta que la independencia judicial constituye el apego del juez al derecho y a la Constitución, conforme al principio de jerarquía normativa consagrado en el artículo $51^{\circ}$ de la Constitución peruana, a pesar de existir una decisión judicial que haya sido emitida debido a un medio impugnatorio por un órgano superior del juez.

Como describe Gorki Gonzales ${ }^{22}$ la sujeción a la Constitución constituye la naturaleza de la independencia judicial. La crítica efectuada por dicho autor radica en entender únicamente la independencia judicial en el escenario del juzgador al solicitársele neutralidad y defensa institucional (o corporativa) frente a otros poderes del Estado. Lo referido con anterioridad es incluso conforme a lo contenido en el artículo $138^{\circ}$ de la Constitución peruana que refiere que la función constitucional tiene un origen político o soberano (debido que emana del pueblo). Como refiere López ${ }^{23}$ :

Su justificación subyace en la soberanía que lo empodera con la facultad (y a su vez el deber) de resolver conflictos intersubjetivos. Claro está que el ejercicio de esa función, para que sea democrática, legítima, requiere de la estricta observancia de las garantías del debido proceso.

\footnotetext{
${ }^{19}$ Castañeda (2007), pp. 87-88.

20 Tribunal Constitucional Peruano, Expediente 00019-2009-AI/TC, 21 de marzo del 2011; Tribunal Constitucional Peruano, Expediente 5765-2007-AA/TC, 31 de marzo del 2010.

${ }^{21}$ Guerra (2007), p. 56.

${ }^{22}$ Gonzáles (2007), pp. 81-82.

${ }^{23}$ López (2016), p. 150.
} 
De lo expuesto, la independencia judicial comprende tanto su faceta de garantía del ciudadano (de defensa de sus derechos) y garantía del juez (prohibición de interferencias en su actividad jurisdiccional). La tesis asumida por el Tribunal Constitucional Peruano se centra en la figura del juzgador (ámbito del juez), lo cual restringe la protección de los derechos fundamentales de las partes.

No estamos afirmando que el Tribunal Constitucional peruano no considere a la independencia judicial como un derecho ciudadano o como un instrumento de defensa de los derechos fundamentales, sino que -reiteramos - otorga mayor importancia a una independencia centrada en el juez y no del ciudadano.

En efecto, en la Sentencia del Expediente $\mathrm{N}^{\circ}$ 0023-2003-AI/TC24 (relacionada a la constitucionalidad de la justicia militar), el Tribunal Constitucional desarrolló jurisprudencialmente el contenido constitucional de la independencia judicial, centrándose en la figura del juez como funcionario que administra justicia, más no como una garantía constitucional del ciudadano (derecho fundamental). Este mismo criterio jurisprudencial ha sido confirmado posteriormente en las Sentencias del Tribunal Constitucional peruano del Expediente $\mathrm{N}^{\circ}$ 0004-2006-PI/TC (fundamento jurídico 18) - Caso Fiscal de Nación contra el Congreso de la República ${ }^{25}$, Expediente $\mathrm{N}^{\circ}$ 00512-2013-PHC/TC (fundamentos jurídicos 3.3.1 al 3.3.2) -Caso Jesús Giles Alipazaga y otros ${ }^{26}$; y Expediente $\mathrm{N}^{\circ}$ 01460-2016-PHC/TC (fundamentos jurídicos 18 y 19) —Caso Alberto Fujimori Fujimori27.

Entender el contenido de la independencia judicial únicamente desde la óptica del juez ha generado que el Poder Judicial no asuma críticas y los jueces se consideren víctimas frente a cuestionamientos por parte de la sociedad ${ }^{28}$.

En tal sentido, la independencia judicial consagrada en el inciso 2) del artículo $139^{\circ}$ de la Constitución Política peruana deberá entenderse como aquella garantía-derecho constitucional que tiene dos ámbitos:

a. El primero, la defensa de la autonomía del juez frente a cualquier intromisión de terceros (del sector público o privado) en las decisiones que adopte en el marco de un proceso judicial.

\footnotetext{
24 Tribunal Constitucional Peruano, Expediente 0023-2003-AI/TC, 09 de junio del 2004. Véase: Fundamento jurídico 31.

25 Tribunal Constitucional Peruano, Expediente 0004-2006-PI/TC, 29 de marzo del 2006.

26 Tribunal Constitucional Peruano, Expediente 00512-2013-PHC/TC, 19 de junio del 2013.

27 Tribunal Constitucional Peruano, Expediente 01460-2016-PHC/TC, 03 de mayo del 2016.

${ }^{28}$ Pásara (2007), p. 105.
} 
Como correlato, existe la prohibición que cualquier persona, Poder del Estado u organismo constitucional autónomo de manera directa o indirecta ejerza influencia sobre el juez para resolver una controversia específica.

b. El segundo, la defensa del Estado de derecho y de la Constitución en los fallos que el juez emita. El juez debe resolver conforme a derecho y a los derechos fundamentales de las personas.

\section{La inaplicación de los precedentes en la jurisprudencia constitucional latinoamericana}

La inaplicación de los precedentes ha sido materia de desarrollo jurisprudencial por órganos judiciales latinoamericanos que resuelven controversias de carácter constitucional, conforme desarrollaremos a continuación:

\subsection{EL EFECTO VINCULANTE DE LOS PRECEDENTES: LA OBLIGATORIEDAD COMO REGLA GENERAL}

A nivel comparado se ha advertido que el efecto vinculante del precedente se rige por su obligatoriedad. En otros términos, los ordenamientos jurídicos consultados parten de la premisa que el precedente emitido por el órgano máximo de control o interpretación constitucional es imperativo frente a cualquier otra autoridad estatal.

En efecto, en el caso de Colombia, la Corte Constitucional, en la Sentencia del 04 de febrero del 2010, sostiene la obligatoriedad absoluta del precedente constitucional, señalando que ante su desacato, desconocimiento u omisión determinan una violación directa de la Constitución, afectando la seguridad jurídica y la unidad del ordenamiento jurídico ${ }^{29}$. Dicha interpretación jurisprudencial ha sido también desarrollada en la Sentencia del 24 de agosto del 2011, que resalta la importancia de los precedentes porque permiten la igualdad y seguridad jurídica ${ }^{30}$.

De lo expuesto, la Corte Constitucional colombiana tiene como regla general que el precedente constitucional es obligatorio de forma absoluta, debido que significa la aplicación inmediata de la Constitución, siendo que cualquier cuestionamiento existente en su aplicación

${ }^{29}$ Corte Constitucional, Expediente T-2364128, 04 de febrero del 2010.

${ }^{30}$ Corte Constitucional, Expediente D-8413, 24 de agosto del 2011. 
(contradicción interna o imprecisión) debe ser resuelta por la misma Corte, quien podrá dejarlo sin efecto de manera motivada.

Por otro lado, el desarrollo jurisprudencial del Tribunal Constitucional Plurinacional boliviano afirma que el precedente tiene efectos vinculantes obligatorios a todos los poderes públicos operadores del derecho, conforme se aprecia en la sentencia del 08 de julio del $2002^{31}$. La obligatoriedad solo se aplica con relación a similitudes en la ratio decidendi de la Sentencia constitucional en referencia al caso en concreto sometido al juez ${ }^{32}$.

El criterio jurisprudencial ha sido confirmado en las sentencias del 16 de febrero del 2005, del 07 de marzo del 2005 y del 05 de julio del 2005, que sostienen que la jurisprudencia constitucional emitida por dicho Tribunal tiene carácter vinculante a todos los poderes públicos, incluyendo las sub reglas de interpretación obtenidas desde la Constitución y contenidas en las sentencias emitidas por este.

En Venezuela, la Sala Constitucional del Tribunal Supremo de Justicia adopta como regla jurisprudencial la obligatoriedad del precedente de forma absoluta, prohibiendo a los jueces inaplicarlo; a diferencia de Colombia y Bolivia. En efecto, en la sentencia del 19 de julio del 2001, la Sala Constitucional realizó una distinción entre las distintas competencias de control constitucional que la Carta Magna le ha otorgado a través de los artículos $334^{\circ}$ y $335^{\circ}$, refiriendo que la norma interpretativa individual al caso concreto, obtenida a través de la jurisdictio, puede ser obligatoria a los demás jueces a través de la técnica del precedente. A tal efecto, se debe analizar si existe una analogía esencial entre el caso resuelto por la Sala Constitucional y el caso sometido al juez ${ }^{33}$.

Por otro lado, en la Sentencia del 18 de junio del 2003, la Sala Constitucional realiza una distinción del efecto vinculante u obligatorio del precedente judicial:

a. El precedente de iure: Correspondiente a las decisiones que emite la Sala Constitucional sobre el contenido y alcances de las normas constitucionales.

b. El precedente de facto: Correspondiente a las decisiones emitidas por las otras Salas del Tribunal Supremo de Venezuela.

31 Tribunal Constitucional Plurinacional, Expediente 2002-04478-09-RII, 08 de julio del 2002.

32 Tribunal Constitucional Plurinacional, Expediente 2002-04478-09-RII, 08 de julio del 2002.

${ }^{33}$ Sala Constitucional del Tribunal Supremo de Justicia de Venezuela, Expediente 01-1362, 19 de julio del 2001. 


\subsection{LA INAPLICACIÓN DEL PRECEDENTE: DEBER DE MOTIVACIÓN E INDEPENDENCIAJUDICIAL}

En la jurisprudencia constitucional latinoamericana analizada se concluye que el efecto vinculante del precedente es obligatorio de manera vertical y horizontal; sin embargo, se permite en determinadas circunstancias que el juez se aparte del mismo, salvo el caso de Venezuela en que dicha posibilidad está prohibida.

En el caso colombiano, la Corte Constitucional, en la Sentencia del 27 de septiembre del 2001, desarrolló la posibilidad de apartamiento del precedente siempre que exista una motivación del juez ${ }^{34}$. En efecto, refiere que la labor de administración de justicia está garantizada a través de las garantías de la independencia judicial (neutralidad y ausencia de injerencias externas) y de autonomía judicial (libertad frente al órgano superior). Sin embargo, menciona que dichas garantías no son fines en sí mismos, sino medios para lograr la vigencia y respeto a la Constitución.

Posteriormente la Corte Constitucional, en la sentencia del 24 de agosto del 2011, señala que la obligatoriedad (o vinculatoriedad) del precedente puede ser dejada sin efecto, excepcionalmente, por los jueces en aplicación de su independencia jurisdiccional ${ }^{35}$, debiéndose cumplir con dos elementos: El primero es la motivación de su decisión y el segundo referido a la interpretación alternativa que se adopte en reemplazo del precedente inaplicado. Debemos resaltar que se exige un grado calificado de motivación judicial al decidir la inaplicación del precedente, conforme a la sentencia del 01 de noviembre del $2011^{36}$.

Por otro lado, el Tribunal Constitucional Plurinacional boliviano, en la Sentencia del 16 de noviembre del 2004, sostiene que la obligatoriedad del precedente no es absoluta, debido que ésta permite al mismo tiempo que los jueces puedan apartarse del mismo, con una motivación adecuada de dicha decisión ${ }^{37}$, criterio que ha sido confirmado en la Sentencia del 05 de julio del $2005^{38}$.

En el caso de Chile, el Tribunal Constitucional no ha desarrollado de manera específica la posibilidad de inaplicación de precedentes vinculantes. Sin embargo, como anota Nogueira

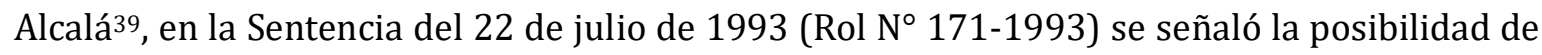

\footnotetext{
${ }^{34}$ Corte Constitucional, Expediente T-454716, 27 de septiembre del 2001.

${ }^{35}$ Corte Constitucional, Expediente D-8413, 24 de agosto del 2011.

${ }^{36}$ Corte Constitucional, Expediente D-8473, 01 de noviembre del 2011.

37 Tribunal Constitucional Plurinacional, Expediente 2004-09677-20-RAC, 16 de noviembre del 2004.

38 Tribunal Constitucional Plurinacional, Expediente 2004-10528-22-RAC, 05 de julio del 2005.

${ }^{39}$ Nogueira (2010), p. 109.
} 
modificación del precedente, al sostener que mantener el mismo criterio interpretativo contenido en una sentencia constitucional para resolver casos futuros permite certeza y seguridad jurídica; sin embargo, se permite el cambio de doctrina jurisprudencial cuando exista una motivación que lo sustente ${ }^{40}$.

De lo expuesto, se confirma que el efecto del precedente es relativo. El juez puede apartarse del precedente en determinadas circunstancias, siempre que exista motivación en la decisión adoptada, conforme a los siguientes criterios:

- Indicación expresa del precedente que es materia de inaplicación en el caso específico.

- Exposición de los argumentos que sustentan la inaplicación del precedente; es decir, el juez debe sustentar los beneficios de su interpretación frente a la interpretación contenida en el precedente.

- La indicación del nuevo criterio interpretativo que sustituye el precedente en el caso.

\section{La inaplicación de los precedentes vinculantes en la jurisprudencia constitucional peruana}

La inaplicación de precedentes vinculantes por los jueces ha sido contradictoria, utilizándose el método analítico. En los datos obtenidos en las búsquedas de jurisprudencias del Tribunal Constitucional y del Poder Judicial en bases de datos, se determinaron los criterios por los cuales los jueces inaplican un precedente y aquellas sentencias del Tribunal Constitucional que anulan resoluciones judiciales por inaplicar un precedente, conforme desarrollaremos a continuación:

\subsection{LA JURISPRUDENCIA DEL TRIBUNAL CONSTITUCIONAL PERUANO FRENTE A LA INAPLICACIÓN DEL PRECEDENTE VINCULANTE}

En los siguientes apartados analizaremos determinados criterios jurisprudenciales emitidos por el Tribunal Constitucional relacionados a la posibilidad de inaplicar un precedente vinculante:

40 Tribunal Constitucional Chileno, Rol N 171-1993, 22 de julio de 1993. 


\section{A. La imposibilidad del juez de inaplicar el precedente por su contenido} (Sentencia del 10 de octubre del 2005 - Caso Municipalidad Distrital de Lurín)

El Tribunal Constitucional mediante Sentencia N²024-2003-AI/TC señala que la aplicación del precedente por el operador jurídico (entiéndase juez) se da por lo siguiente: Primero, por la existencia de similitudes de hecho entre el caso a resolver por el juez y el precedente; y segundo, si existen diferencias (pero también similitudes), entre el caso a resolver y el precedente, se puede aplicar si es que éstas no generan un trato distinto.

En conclusión, el juez puede tener un margen de decisión en la aplicación del precedente. El juez únicamente puede apartarse del precedente si los hechos del caso que tiene que resolver no encajan en él.

\section{B. La independencia judicial es inválida para inaplicar un precedente} (Sentencia del 13 de febrero del 2007 - Caso Ministerio de Comercio Exterior vs. El Poder Judicial)

En el fundamento jurídico 46 de la Sentencia $\mathrm{N}^{\circ}$ 006-2006-PC/TC, el Tribunal Constitucional señaló que el juez ordinario no puede ampararse en su independencia para desvincularse de las Sentencias del Tribunal Constitucional. Por tanto, los límites del Poder Judicial son las Sentencias del Tribunal Constitucional y los precedentes vinculantes emitidos por este.

\section{La imposibilidad de cuestionamiento del precedente por el Poder Judicial} (Sentencia del 04 de junio del 2010 - Caso Transportes VEA S.A.C. (Precedente vinculante)

El Tribunal Constitucional, mediante Sentencia $N^{\circ}$ 5961-2009-AA/TC, señala que el Poder Judicial ha estado emitiendo sentencias contradictorias a su jurisprudencia, contraviniendo lo establecido en el tercer párrafo del artículo VI del Título Preliminar del Código Procesal Constitucional.

Cabe señalar que, en aplicación del artículo VII del Título Preliminar del Código Procesal Constitucional peruano, el Tribunal Constitucional procede a fijar un precedente vinculante que confirma la constitucionalidad de las normas jurídicas cuestionadas (que no son atentatorias a las libertades de empresa, contratación, trabajo e iniciativa privada).

En efecto, los criterios jurisprudenciales contenidos en las Sentencias de los Expedientes $\mathrm{N}^{\circ}$ 00024-2003-AI/TC, $N^{\circ}$ 03741-2004-PA/TC y $N^{\circ}$ 03908-2007-PA/TC (mencionados en la 
Sentencia $\mathrm{N}^{\circ}$ 5961-2009-AA/TC) desarrollan los presupuestos básicos para generar un precedente vinculante conforme al mandato del artículo VII del Título Preliminar del Código Procesal Constitucional.

El precedente vinculante establecido en la Sentencia, que conforme al artículo VII del Título Preliminar del Código Procesal Constitucional, determina su obligatoriedad a todos los poderes públicos; y en consecuencia, cualquier sentencia anterior emitida en contravención al precedente vinculante aprobado es ineficaz.

Finalmente, en el fundamento jurídico 19, el Tribunal Constitucional reitera lo señalado en anteriores jurisprudencias: Que no es el único intérprete de la Constitución, sin embargo, le corresponde decidir en última palabra qué es o no constitucional, y ningún Poder u órgano constitucional puede contradecirlo o desvincularse de sus decisiones.

\section{La imposibilidad de cuestionamiento del precedente por el Poder Judicial} (Sentencia del 12 de agosto del 2010 - Caso Poder Ejecutivo vs. Poder Judicial)

Mediante Sentencia $N^{\circ}$ 00001-2010-CC/TC, el Tribunal Constitucional señala que el Poder Judicial es competente formal y materialmente para emitir resoluciones judiciales que controlen los actos del Poder Ejecutivo. Situación distinta es si esas decisiones judiciales contravienen la Constitución o interpretaciones que el Tribunal Constitucional realiza a través de su jurisprudencia.

No se cuestiona la competencia constitucional del Poder Judicial en emitir sentencias, sino en el contenido de las mismas. Por tanto, si son contrarias al precedente, son nulas.

E. La imposibilidad e invalidez de inaplicar un precedente vinculante por el Poder Judicial (Sentencia del 19 de abril del 2011 - Caso Grela Eufemia Felipe de Alcalde vs la ONP)

El Tribunal Constitucional por Sentencia N 0525-2011-PA/TC resuelve desestimando la Demanda interpuesta, señalando en el fundamento jurídico 2, que ha tomado conocimien to de la Sentencia emitida por la Primera Sala Civil de la Corte Superior de Justicia de Lima que inaplicó el precedente de la STC 1417-2005-PA/TC del 12 de julio del 2015 porque está desfasado, disponiendo el aumento de la pensión a favor de la demandante. 
Finalmente, en los fundamentos jurídicos 3 al 5, el Tribunal Constitucional exhorta al Poder Judicial cumplir los precedentes vinculantes conforme al artículo VII del Título Preliminar del Código Procesal Constitucional.

F. La imposibilidad e invalidez de inaplicar un precedente vinculante por el Poder Judicial (Sentencia del 28 de marzo del 2014 - Caso José María Távares)

El Tribunal Constitucional, mediante Sentencia № 03950-2012-PA/TC, declaró fundada la Demanda de Amparo interpuesta. En el fundamento jurídico 9, la Sentencia refiere que la violación de la doctrina jurisprudencial (se entiende vinculante) atenta contra la seguridad jurídica y predictibilidad de las decisiones.

Finalmente, en el fundamento jurídico 10 de la Sentencia, el Tribunal Constitucional señala que no puede anular retroactivamente decisiones de otros poderes públicos (incluye al Poder Judicial) que son contrarias a la doctrina vinculante emitida por éste, sin embargo, no se puede acatar dicha decisión.

\subsection{LA JURISPRUDENCIA DEL PODER JUDICIAL RESPECTO A LA INAPLICACIÓN DEL PRECEDENTE VINCULANTE}

El Poder Judicial en algunos casos específicos ha desarrollado posiciones contradictorias con relación a la posibilidad de inaplicar un precedente vinculante, conforme desarrollamos en los apartados siguientes:

\section{A. La aplicación obligatoria del precedente vinculante (Sentencia de la Sala} Civil de Tacna del 24 de septiembre del 2010)

En el presente caso, la Sala Civil de Tacna mediante Resolución de Vista (emitido en el cuaderno cautelar) $N^{\circ} 11$ del 12 de enero del 2010, declaró suspender los efectos del Decreto de Urgencia $N^{\circ} 050-2008$, señalando que el mismo no cumplía los parámetros para su validez constitucional, debido que regulaba temas distintos al económico, como la protección de los intereses de los usuarios y no era de carácter extraordinario; sino que, conforme a la propia redacción de la norma mencionada, es parte de una política permanente del Estado.

Este es uno de los casos que el Tribunal Constitucional consideró inválido por inaplicar el precedente relacionado a la importación de automóviles usados, conforme a las sentencias $\mathrm{N}^{\circ}$ 5961-2009-AA/TC y No 00001-2010-CC/TC. Cabe mencionar que la inaplicación del precedente vinculante no fue expresamente mencionada por la Sala Civil de Tacna al momento 
de resolver inicialmente el proceso de amparo. Sin embargo, dicho órgano jurisdiccional en función al mandato establecido por el Tribunal Constitucional procedió a aplicar posteriormente el precedente, dejando sin efecto su decisión anterior.

\section{B. La inaplicación del precedente sólo en su contenido fáctico excluyendo el} contenido jurídico (Sentencia emitida por el Juzgado Mixto del Módulo Básico de la Esperanza del 24 de julio del 2015)

El 17 de julio del 2014, Nelson Jubenal Flores Ayllón interpone Demanda contra el Proyecto Especial Chavimochic y el Gobierno Regional de La Libertad, solicitando la inaplicación de los Contratos Administrativos de Servicios (CAS) suscritos a partir de julio del 2008 hasta la actualidad, la cual es tramitada mediante el Expediente $\mathrm{N}^{\circ}$ 058-2014-0-1618-JM-LA-01.

En la Sentencia de primera instancia, el Juzgado considera relevante verificar si se aplica o no el precedente vinculante emitido por el Tribunal Constitucional en el Expediente $\mathrm{N}^{\circ} 5057$ 2013-PA/TC (Caso Rosalía Beatriz Huatuco Huatuco), relacionado a desnaturalización por contratos en la modalidad de CAS.

El juez formula la siguiente interrogante: ¿Pueden los jueces laborales apartarse de los precedentes constitucionales vinculantes? En tal sentido, señala que conforme a lo establecido en el artículo VII del Título Preliminar del Código Procesal Constitucional y el artículo IV del Título Preliminar de la Ley Procesal de Trabajo, la respuesta sería negativa debido que el Tribunal Constitucional ha adoptado una teoría de "autoritarismo inflexible" del precedente. Sin embargo, existen supuestos en los cuales el juez se puede apartar del precedente.

Partiendo de la premisa que los precedentes vinculantes son una técnica jurídica, el juez considera que se puede aplicar al presente caso la técnica del distinguishing, que consiste en no aplicar el precedente vinculante debido que en el caso concreto no concurren los mismos presupuestos de hecho que han justificado la adopción del mismo.

En otros términos, el juez inaplica un precedente vinculante, pero no por ser inconstitucional, sino porque el supuesto de hecho del precedente es inaplicable al caso. Es decir, existen aspectos específicos del precedente vinculante (fácticos) que no se aprecian en el caso sometido al juez. 


\section{La inaplicación del precedente por ser contrario a la Constitución} (Sentencia emitida por la Cuarta Sala Laboral de Lima del 17 de julio del 2015)

En el proceso laboral seguido por doña Ruth Madeleyne Vilca Vilca contra el Poder Judicial correspondiente al Expediente $N^{\circ} 27013-2013$, se emitió la Sentencia № 137-2014-03-JTL del 02 de junio de 2014. La Sala Laboral sostiene, en principio, que los jueces laborales no pueden inaplicar el precedente vinculante en la regla que establece, salvo el distinguishing.

Sin embargo, esto no impide a la Sala mostrar su discrepancia con el precedente cuando agravia la dignidad de la persona humana y los derechos laborales constitucionales reconocidos al trabajador (principio protector, principio de condición más beneficiosa o progresividad, el principio de igualdad y la eficacia horizontal de los derechos fundamentales).

En consecuencia, conforme dichos criterios, el juzgador considera que el precedente vinculante del Expediente $\mathrm{N}^{\circ}$ 5057-2013-PA/TC colisiona con el principio-derecho de igualdad, afecta el principio de continuidad laboral con relación a trabajadores cuyo régimen laboral es impuesto por el empleador; y vulnera el principio de condición más beneficiosa, pues establece nuevas condiciones en perjuicio del trabajador.

En conclusión, el Poder Judicial considera inaplicar el precedente por contravenir la Constitución, porque desprotege al trabajador y genera desigualdad frente a otros casos distintos al precedente, siendo un caso de abierta discrepancia con el precedente vinculante por ser inconstitucional.

\section{La compatibilidad de la independencia judicial y la facultad de inaplicar un precedente vinculante en el ordenamiento jurídico peruano}

Si bien lo desarrollado en apartados anteriores puede denotar que en el ordenamiento jurídico peruano es imposible, vía judicial, inaplicar precedentes vinculantes, consideramos que no es correcto, conforme expondremos a continuación:

\subsection{LA AFECTACIÓN DE LA INDEPENDENCIA DEL JUEZ ANTE UN PRECEDENTE VINCULANTE INCONSTITUCIONAL}

El efecto vinculante de los precedentes emitidos por el Tribunal Constitucional peruano conforme al artículo VII del Título Preliminar del Código Procesal Constitucional es de carácter 
absoluto en su eficacia vertical. Es más, cuando un juez inaplica un precedente vinculante genera responsabilidad administrativa o funcional a través del órgano de control de la Magistratura y responsabilidad penal a través de la configuración del delito de prevaricato por el Ministerio Público.

Con relación a la responsabilidad administrativa —-funcional, la Resolución OCMA N $021-$ 2006/PJ del 04 de abril del 2006, emitida por la Oficina de Control de la Magistratura del Poder Judicial Peruano (OCMA), señala que las sentencias del Tribunal Constitucional que establecieron los precedentes vinculantes $\mathrm{N}^{\circ}$ 206-2005-PA/TC (Laboral) y $\mathrm{N}^{\circ}$ 4227-2005PA/TC (Tragamonedas) deben ser acatadas de manera obligatoria por los Magistrados del Poder Judicial en aplicación del artículo VII del Título Preliminar del Código Procesal Constitucional. Asimismo, se señala que el incumplimiento de los precedentes vinculantes genera afectación al Debido Proceso, al no aplicar una decisión con contenido normativo, conforme al artículo $184^{\circ}$ inciso 1) de la Ley Orgánica del Poder Judicial, incurriendo en responsabilidad funcional establecida en el artículo $201^{\circ}$ inciso 1) de la mencionada ley.

Respecto a la responsabilidad penal, el Ministerio Público del Perú, mediante la Resolución de la Fiscalía de la Nación Nº41-2010-MP-FN del 13 de febrero del 2010, estipuló que los jueces que emitan resoluciones contrarias a precedentes vinculantes emitidos por el Tribunal Constitucional incurren en el delito de prevaricato de manera indirecta, debido que existen normas legales procesales expresas que señalan la aplicación obligatoria del precedente vinculante.

En efecto, el delito de prevaricato contenido en el artículo $418^{\circ}$ del Código Penal peruano sanciona al juez que dicta una decisión jurisdiccional contrario al texto expreso y claro de la ley, siendo que una de sus modalidades es la transgresión de una norma cuya interpretación no genera dudas, que en la Resolución mencionada son la Ley $\mathrm{N}^{\circ} 27153$, la Ley $\mathrm{N}^{\circ} 27796$, los artículos VI y VII del Título Preliminar del Código Procesal Constitucional y la Primera Disposición Final de la Ley Orgánica del Tribunal Constitucional, que señalan la aplicación obligatoria del precedente vinculante.

En otro aspecto, de la revisión de las sentencias emitidas por el Tribunal Constitucional Peruano se evidencia que a pesar de que se reconoce la independencia del juzgador al momento de resolver una controversia en la que se debe aplicar el precedente vinculante, no se le permite apartarse del mismo debido a tres razones: 
a. La primera es estrictamente legal y está referida a la prohibición contenida en el artículo VII del Código Procesal Constitucional, que señala el efecto obligatorio y erga omnes del precedente. Adicionalmente, el único órgano que puede apartarse del precedente es el Tribunal Constitucional, siempre y cuando exprese los motivos por los cuales se aparta del precedente.

b. La segunda está referida a la naturaleza misma del precedente. Recordemos que éste es una técnica jurídica que permite otorgar mayor certeza, predictibilidad y seguridad al momento de resolver las controversias, debido que los operadores jurídicos conocen de manera previa cómo el juez decidirá el caso. Es decir, el precedente permite uniformidad en la aplicación e interpretación del derecho.

c. Finalmente, existe un factor subjetivo que es el temor del juez de exponer su criterio jurisdiccional debido que existe la posibilidad que sea denunciado penalmente o sea sancionado por inconducta funcional al apartarse del precedente.

Es más, lo expuesto ha sido confirmado aún más con las propias Sentencias del Tribunal Constitucional, en las que se confirma la obligatoriedad de los precedentes vinculantes, sin posibilidad que el juez pueda apartarse de los mismos a pesar de la motivación que pudiera existir en ejercicio de su independencia jurisdiccional, debido que la competencia respecto a lo que se debe considerar constitucional o no es del propio Tribunal Constitucional.

Está demostrado que algunos jueces cuando han preferido apartarse de un precedente lo han realizado de forma relativa a través de la figura del distinguishing que constituye un método que confirma la obligatoriedad absoluta del precedente constitucional. Es decir, prima facie, se pretende aplicar el precedente, pero no se arriba a dicho resultado porque uno de sus elementos no se configura en el caso.

Se ha comprobado dos casos en los cuales el juez se aparta de la aplicación del precedente vinculante. El primero está referido a la Sentencia emitida por la Cuarta Sala Laboral de Lima del Expediente $\mathrm{N}^{\circ}$ 27013-2013, debido al conflicto expreso del precedente con normas constitucionales en materia laboral y el principio de igualdad ante la ley. El segundo está contenido en una Sentencia del Tribunal Constitucional (Caso Grela Eufemia Felipe de Alcalde) en el cual una Sala Civil de la Corte Superior de Justicia de Lima inaplica un precedente debido que era desfasado porque no permitía una pensión adecuada y legítima a la beneficiaria.

Estos últimos casos nos permiten acreditar dos cuestiones específicas: 
a. La inaplicación del precedente vinculante por un juez se realiza por proteger un derecho o bien constitucional. Si bien el precedente contiene una interpretación jurisprudencial realizada por el Tribunal Constitucional, su aplicación genera un daño colateral a otro derecho constitucional que debe ser objeto de tutela en el caso específico.

b. La inaplicación del precedente vinculante por un juez no es frecuente en el sistema judicial peruano.

Se aprecia jurisprudencia que se aparta tácitamente (por omisión) de un precedente vinculante, en los casos referidos a la importación de automóviles usados y de licencia para operar empresas de tragamonedas y casinos, que han sido mencionados en las Sentencias del Tribunal Constitucional de los Expedientes N 006-2006-PC/TC y Nº0001-2010-CC/TC. Sin embargo, estos casos no nos permiten demostrar cuál fue la motivación del juzgador al no aplicar el precedente.

Sin embargo, podemos afirmar que el Poder Judicial peruano alega, como defensa de las mencionadas sentencias, la independencia judicial como competencia constitucional contenida en el numeral 2) del artículo $139^{\circ}$ de la Constitución peruana. En otros términos, es el juez, en su criterio independiente y sin injerencia externa al momento de resolver una controversia, quien decide no aplicar un precedente vinculante del Tribunal Constitucional.

En este punto, no es criterio válido que el Tribunal Constitucional considere que tiene competencia exclusiva y excluyente en la interpretación constitucional a través de los precedentes vinculantes que emite. La Constitución peruana no señala expresamente dicha competencia del Tribunal Constitucional (solo lo refiere una norma de rango legal como el artículo VII del Título Preliminar del Código Procesal Constitucional).

En efecto, el Tribunal Constitucional es uno de los intérpretes de la Constitución. García Toma, en interpretación del artículo $202^{\circ}$ de la Constitución peruana, refiere que “(...) el inciso 1 del artículo 202 y el inciso 4 del artículo 200 de la Constitución señalan el deber funcional de los magistrados de este ente de declarar - previa labor interpretativa- el sentido de lo constitucional o inconstitucional de aquellas normas con jerarquía o condición de ley”. Sin embargo, el mismo autor, en posición que compartimos, refiere que también el Poder Judicial, conforme al artículo $138^{\circ}$ de la Constitución, tiene esa misma potestad cuando establece el 
deber funcional de los jueces (a través de la interpretación) de preferir la norma constitucional ante incompatibilidad con otra norma de menor jerarquía 41.

De lo expuesto, el Tribunal Constitucional no es el único intérprete de la Constitución, siendo que ninguna norma constitucional refiere dicha competencia específica, sino que es uno de los distintos intérpretes de la misma, conforme al numeral 1) del artículo $202^{\circ}$ de la Constitución Peruana.

En resumen, existe una afectación a la independencia judicial cuando el juez se encuentra restringido de inaplicar un precedente contrario a la Constitución, por lo siguiente:

a. Si entendemos la independencia como falta de injerencia externa en la competencia del juez para resolver el caso, la obligatoriedad del precedente contrario a la Constitución constituye una intromisión ilegítima del Tribunal Constitucional, al impedir al juez que exponga los motivos por los cuales no considera aplicarlo.

b. Constituye también una afectación a la independencia judicial el hecho que el juez se encuentre sujeto a la posibilidad de ser investigado penalmente por la comisión de un delito o ser investigado administrativamente por infracción funcional por ejercer una competencia que le otorga la misma Constitución para defenderla. En otros términos, se genera una intromisión indirecta en la decisión del juzgador que considere apartarse de un precedente ilegítimo constitucionalmente si está bajo la amenaza de ser denunciado penal y administrativamente por dicha decisión.

c. La independencia judicial constituye una garantía constitucional que no puede ser limitada por una prohibición legal establecida en una norma de menor jerarquía como el artículo VII del Título Preliminar del Código Procesal Constitucional.

d. La independencia judicial no solo es una garantía constitucional intrínseca al juez, sino también es un derecho fundamental (integrante del Debido Proceso) de las partes del proceso. Restringir la independencia judicial afecta tanto al juez como a las partes del proceso al impedir que se aplique la Constitución frente a un precedente contrario a ésta.

\footnotetext{
${ }^{41}$ García Toma (2011), p. 65.
} 
e. Resulta errado señalar que el problema descrito se limita a un asunto de competencias constitucionales entre el Tribunal Constitucional y el Poder Judicial. Estamos ante un asunto de defensa de la propia Constitución que debe ser garantizado por el Tribunal Constitucional, los Poderes del Estado y los ciudadanos. A tal efecto, el artículo $38^{\circ}$ de la Constitución peruana señala que todos los peruanos tienen la obligación de cumplir y defender la Constitución.

Complementariamente, el juez peruano tiene la facultad constitucional a través del ejercicio de su independencia judicial de apartarse o inaplicar un precedente vinculante, conforme a lo establecido expresamente en el inciso 2) del artículo $139^{\circ}$ de la Constitución peruana ${ }^{42}$, teniendo en consideración lo siguiente:

a. La inaplicación del precedente vinculante debe ser en defensa de la Constitución. Es decir, debe existir una incompatibilidad en el caso concreto entre el precedente vinculante y la Constitución, sea en la forma o en el fondo.

b. La inaplicación del precedente vinculante debe ser expresa, es decir, no tácita ni por omisión del mismo.

c. La inaplicación del precedente vinculante debe ser motivada por el juez, para conocer los argumentos por los cuales adopta dicha decisión.

En consecuencia, la independencia del juez peruano se afecta en el proceso cuando tiene que aplicar obligatoriamente un precedente vinculante inconstitucional.

\subsection{LA INDEPENDENCIA JUDICIAL COMO CRITERIO VÁLIDO PARA LA INAPLICACIÓN DEL PRECEDENTE VINCULANTE INCONSTITUCIONAL}

El juez peruano puede inaplicar un precedente vinculante en una controversia específica cuando sea contrario a la Constitución, en la forma o en el fondo. En una revisión de la jurisprudencia peruana, la inaplicación expresa de un precedente vinculante se realiza cuando existe una incompatibilidad entre el precedente y un derecho constitucional.

Si bien las sentencias a nivel nacional hacen referencia a contradicciones entre el precedente y derechos constitucionales sustantivos, no es impedimento para aplicar el mismo

\footnotetext{
${ }^{42}$ Cabe mencionar que adicionalmente el artículo $51^{\circ}$ de la Constitución peruana consagra el principio de jerarquía normativa que señala: "La Constitución prevalece sobre toda norma legal; la ley, sobre las normas de inferior jerarquía, y así sucesivamente. La publicidad es esencial para la vigencia de toda norma del Estado".
} 
criterio cuando el conflicto sea también a nivel de forma. Si bien no se ha encontrado jurisprudencia nacional sobre el particular (ni tampoco la extranjera consultada), consideramos que el conflicto formal se acredita cuando la incompatibilidad del precedente esté relacionada a su procedimiento de aprobación; es decir, que no haya cumplido con los requisitos necesarios para ser considerado como tal.

En estricto el defecto en la forma del precedente vinculante está referido específicamente a una afectación al debido proceso, es decir al procedimiento establecido por la ley para su aprobación.

Debido a los pocos supuestos nacionales de apartamiento del precedente por contravención de fondo de la Constitución, la jurisprudencia internacional revisada en el presente trabajo nos otorga algunos criterios que pueden aplicarse al caso peruano:

a. Debemos partir de la obligatoriedad de la aplicación precedente por el juez. La inaplicación del precedente es excepcional y sujeta a determinadas circunstancias.

b. En caso de que el juez decida en un caso específico apartarse del precedente, se debe sustentar en la existencia de un conflicto esencial con una norma constitucional, que resulta necesaria para la solución de la controversia. A tal efecto, el juez debe valorar que la interpretación de la norma constitucional en conflicto sea más favorable a la regulada en el precedente vinculante. Esto significa que debe realizar una ponderación de los bienes constitucionalmente protegidos tanto por el precedente (si existiera) frente al bien constitucionalmente protegido que se le contrapone.

c. El juez que inaplica un precedente tiene una obligación de motivar o justificar la decisión. Consideramos pertinente aplicar en el presente caso, los criterios desarrollados por la jurisprudencia constitucional boliviana y colombiana, conforme a lo siguiente:

- Indicación expresa del precedente que es materia de inaplicación, en el caso específico.

- Exposición de los argumentos por los cuales se considera que se debe inaplicar el precedente. Los mismos deben referirse a los beneficios de la interpretación que realiza el juez frente a la interpretación contenida en el precedente. 
- La exposición del nuevo criterio interpretativo que sustituye el precedente en el caso específico.

d. Consecuentemente, está proscrita cualquier tipo de discrecionalidad o arbitrariedad en la inaplicación del precedente, entendida esta como la falta de motivación o exposición de fundamentos por los cuales se arriba a dicha decisión. No existe la posibilidad de inaplicación tácita del precedente vinculante, debido que, en estricto, supondría una falta o inexistencia de motivación.

Con los criterios antes expuestos, un juez de manera legítima puede apartarse de un precedente vinculante, en ejercicio de su independencia judicial, sin posibilidad de cuestionamiento alguno posterior sea de carácter funcional o penal, más aún si es una garantía constitucional inherente a la función de juzgar.

\subsection{CONDICIONES O PARÁMETROS POR LOS CUALES UN JUEZ PUEDE INAPLICAR UN PRECEDENTE VINCULANTE}

En función a lo desarrollado en el apartado anterior, el precedente constitucional vinculante puede ser inaplicado por el juez cuando:

\section{A. Primer parámetro o condición. El precedente vinculante sea relevante} para resolver la controversia por parte del juzgador

Este parámetro lo denominaremos como la relevancia del precedente vinculante para resolver la controversia. El juzgador al momento de resolver una controversia debe determinar en primer término los hechos que han sido probados en el proceso. Se entiende que aquellos hechos probados son los relevantes para sustentar su decisión.

De manera posterior, debe decidir las normas jurídicas aplicables a la controversia, entre las que se incluyen los precedentes debido a su carácter normativo. En esta etapa, si un precedente regula una situación de hecho referida a la controversia, entonces deberá concluir que éste es relevante o importante para resolver la misma.

Es decir, el juzgador deberá realizar un ejercicio intelectual que concluya que el precedente vinculante resulte aplicable al caso, a través de la revisión de los hechos probados del caso y la regla contenida en el precedente. Debemos recordar que el precedente no solo constituye una 
técnica jurídica jurisprudencial, sino también una regla normativa que contiene elementos fácticos y jurídicos generales.

La relevancia del precedente constitucional solo aplica en aquellos casos que está referido directamente a la controversia principal. En tal sentido, se encuentran excluidos aquellos supuestos referidos a aspectos accesorios de la controversia, a pesar de que sean regulados por un precedente. En este último caso se advierte que no estamos ante un aspecto fundamental para resolver el conflicto por el juzgador.

En este punto es necesario también distinguir este parámetro de la figura del distinguishing, debido que esta parte de la premisa que el precedente vinculante es relevante para resolver la controversia por los hechos contenidos en el caso; sin embargo, por diferencias en uno o más elementos fácticos específicos regulados en el precedente deviene en inaplicable.

En el caso del distinguishing estamos en una etapa intelectual distinta del juzgador, debido que es posterior a la elección de las normas aplicables al caso. La técnica de distinguishing supone una etapa de subsunción de los hechos probados del caso con las reglas normativas que están contenidas en el precedente. En otros términos, estamos ante una etapa de aplicación o no aplicación del precedente.

La relevancia del precedente se refiere a una etapa anterior a la descrita, que está referida a un análisis en la que se escogen las normas y reglas jurídicas esenciales para resolver el conflicto.

Finalmente, debemos distinguir esta condición con el prospective overruling debido que este instituto también se incorpora en el análisis posterior a la elección del bagaje normativo aplicable al caso.

\section{B. Segundo parámetro o condición. El precedente vinculante debe ser} contrario a la Constitución en la forma o en el fondo

Este parámetro lo denominaremos como el tipo de incompatibilidad del precedente con la norma constitucional. Como hemos referido en apartados anteriores, la incompatibilidad puede ser de forma o de fondo. 
Con relación a la incompatibilidad constitucional por la forma, reiteramos que la misma está referida a la afectación al derecho al debido proceso en su manifestación de la garantía de respeto al procedimiento predeterminado por la ley.

En una revisión del artículo $10^{\circ}$ del Reglamento Normativo del Tribunal Constitucional se advierte que el procedimiento específico para aprobar un precedente es de cuatro votos en un mismo sentido resolutivo ${ }^{43}$. Por ejemplo, estaríamos ante un procedimiento ilegal o irregular si un precedente vinculante es aprobado por tres votos del Pleno del Tribunal Constitucional o por una de las dos Salas del Tribunal Constitucional (conformadas por tres Magistrados).

En dichos supuestos existiría una afectación del precedente vinculante en la forma de su aprobación, y por ende una afectación al debido procedimiento establecido por las normas reglamentarias del Tribunal Constitucional.

En el caso de la incompatibilidad por el fondo, el juzgador deberá advertir que la aplicación del precedente resulta contraria a un derecho constitucional de titularidad de una de las partes del proceso, teniendo en consideración lo siguiente:

a. El precedente vinculante es una técnica jurídica que tiene por objeto la protección de la seguridad jurídica y el derecho a la igualdad ante la ley, que tienen rango y tutela constitucional. Asimismo, cabe mencionar que dependiendo del contenido del precedente puede protegerse algunos bienes o derechos constitucionales específicos.

b. La aplicación del precedente vinculante debe agraviar el contenido esencial de un derecho constitucional, que es definido como “(...) aquel núcleo mínimo e irreductible que posee todo derecho subjetivo reconocido en la Constitución, que es indisponible para el legislador, debido que su afectación supondría que el derecho pierda su naturaleza y entidad."44. El juez deberá previamente definir el contenido esencial del derecho constitucional afectado y ver si es incompatible con el precedente.

\footnotetext{
${ }^{43}$ Artículo 10. El quórum del Pleno del Tribunal Constitucional es de cinco de sus miembros.

El Pleno del Tribunal resuelve y adopta acuerdos por mayoría simple de votos emitidos, salvo para resolver la inadmisibilidad de una demanda de inconstitucionalidad o para dictar sentencia que declare la inconstitucionalidad de una norma con rango de ley, casos en los que se exigen cinco votos conformes.

De no alcanzarse la mayoría calificada de cinco votos en favor de la inconstitucionalidad de la norma impugnada, el Tribunal dictará sentencia declarando infundada la demanda de inconstitucionalidad.

Para aprobar un precedente y para establecer, con carácter vinculante, interpretaciones sobre el contenido normativo de las disposiciones con rango de ley, conforme a la Constitución, se requiere cuatro votos en un mismo sentido resolutivo.

En ningún caso el Tribunal Constitucional puede dejar de resolver."

44 Tribunal Constitucional Peruano, Expediente 1042-2002-AA/TC, 06 de diciembre del 2002.
} 


\section{Tercer parámetro o condición. No exista forma por la cual el juzgador pueda evitar la inaplicación del precedente vinculante al resolver la controversia}

Este parámetro lo denominaremos como la última ratio en la decisión de inaplicación del precedente. En efecto, después de advertir la incompatibilidad del precedente con la Constitución sea por la forma o por el fondo, el juez debe analizar si resulta necesario apartarse del precedente.

En el caso de la incompatibilidad formal, este análisis no requiere mayor debate debido que el precedente vinculante tiene un defecto de origen que afecta directamente el contenido esencial del derecho al Debido Proceso al no seguir el procedimiento establecido para su aprobación por el Tribunal Constitucional.

Con relación a la incompatibilidad por el fondo, consideramos que el juez deberá ponderar si la afectación al contenido esencial del derecho fundamental es de tal magnitud que impide su realización efectiva por aplicación del precedente. Es decir, el juez deberá analizar si existe justificación razonable para afectar el derecho fundamental, no debiendo existir otro medio alternativo que permita una mayor afectación que la producida por parte del precedente.

En otros términos, el juez debe verificar si la afectación al contenido esencial del derecho fundamental por el precedente es de tal magnitud, que no existan otros medios más gravosos. Si existieran otros medios más graves, entonces, el juez deberá aplicar el precedente vinculante.

Si no existen otros medios más graves, el juez debe inaplicar el precedente. Es decir, es una decisión de última ratio. Sin embargo, el juzgador no solo debe decidir apartarse del precedente, sino también exponer los fundamentos por los cuales inaplica el precedente y la solución alternativa para la protección del derecho fundamental afectado.

En efecto, debemos recordar que el precedente es una regla normativa jurisprudencial que regula una situación de hecho con determinadas consecuencias jurídicas. La inaplicación del precedente significa que no se realizarán los efectos jurídicos que regula y ante esta situación de anomia normativa, el juez está en la obligación de exponer cuál es la decisión alternativa que impida la afectación de los derechos fundamentales contrarios al precedente y los efectos jurídicos de los mismos. 
En consecuencia, el juez debe realizar una doble labor jurisprudencial debido que no solo debe sustentar el apartamiento del precedente, sino que adicionalmente debe construir una solución alternativa que permita la protección de los derechos fundamentales que pudieron ser afectados con este. Esto dependerá de cada caso en concreto y debe ser debidamente motivado.

\subsection{LOS EFECTOS INTERPARTES DE LA INAPLICACIÓN JUDICIAL DEL PRECEDENTE VINCULANTE}

De lo expuesto, concluimos que la inaplicación del precedente vinculante solo involucra al caso en concreto. De la revisión de la jurisprudencia tanto nacional como extranjera, el juez decide apartarse del precedente en el marco de una controversia específica, razón por la cual el efecto es interpartes.

Por tanto, si bien el precedente vinculante tiene efectos erga omnes, su inaplicación tiene efecto solo para el caso en concreto, debido a las particulares características del mismo que hacen que el juzgador decida apartarse del mismo. Sostener lo contrario implicaría otorgar al juez la potestad de emitir una regla normativa que está vedada por el ordenamiento jurídico peruano tanto por la Constitución como por las normas de rango legal e infralegal.

Lo expuesto no impide que el juzgador pueda decidir la inaplicación del precedente en controversia similar, siendo que el análisis correspondiente se efectúa en función a los elementos fácticos específicos del caso similar, más no como una regla jurídica con carácter general. De manera similar, el juez puede decidir aplicar el precedente si considera que no existen motivos suficientes para su inaplicación en ejercicio de su independencia judicial.

Como se puede advertir, el efecto interpartes de la inaplicación del precedente es producto de la labor intelectual descrita con anterioridad, la cual — reiteramos- debe ser debidamente motivada.

\section{Conclusiones}

La jurisprudencia del Tribunal Constitucional peruano reconoce la garantía de la independencia del juez peruano al momento de resolver las controversias que son sometidas a su conocimiento; sin embargo, se le impide apartarse de un precedente vinculante debido a la restricción del artículo VII del Título Preliminar del Código Procesal Constitucional, la 
naturaleza jurídica del precedente y el temor a que sea denunciado administrativamente y penalmente.

La jurisprudencia nacional emitida por el Poder Judicial que ha inaplicado un precedente vinculante se ha sustentado en la protección de derechos constitucionales que son afectados por este. Asimismo, lo expuesto se ha comprobado a través de la jurisprudencia internacional comparada.

La jurisprudencia del Tribunal Constitucional revisada demuestra que el fundamento principal por el cual los jueces defienden las decisiones por las que se apartan de un precedente es la protección de la garantía de la independencia juridicial, consagrada en el inciso 2) del artículo $139^{\circ}$ de la Constitución Política peruana.

Por tanto, está comprobado que existe una afectación a la independencia judicial cuando el juez está impedido de inaplicar un precedente vinculante contrario a la Constitución, porque:

- Constituye una intromisión ilegítima del Tribunal Constitucional en sus decisiones.

- La independencia judicial se afecta cuando el juez estaría sujeto a una denuncia penal o administrativa al ejercer una competencia que le otorga la misma Constitución.

- La independencia judicial tiene rango constitucional, mientras que la prohibición de inaplicación de precedentes tiene rango legal contenido en el Código Procesal Constitucional.

- La restricción de la independencia judicial no solo afecta al juez, sino a las partes, más aún si esta es un derecho constitucional integrante del debido proceso.

En consecuencia, el juez peruano tiene la facultad constitucional, a partir de su independencia judicial, de inaplicar un precedente vinculante por ser contrario a la Constitución sea en la forma o en el fondo. En otros términos, debe existir una afectación específica de un derecho constitucional en agravio de una de las partes del proceso, siendo que la inaplicación del precedente debe ser expresa y motivada por el juez.

La afectación por la forma en la Constitución por un precedente vinculante está referida al procedimiento establecido por ley para su aprobación (a través del Reglamento Normativo del 
Tribunal Constitucional), lo que significa una afectación al derecho constitucional al Debido Proceso en su manifestación del procedimiento preestablecido.

Con relación a la afectación por el fondo de la Constitución a través del precedente, la jurisprudencia internacional nos brinda los siguientes criterios aplicables al presente trabajo:

- La inaplicación del precedente es de carácter excepcional y sujeta a determinados parámetros.

- Debe existir un conflicto directo entre el precedente y una norma constitucional necesaria para resolver la controversia.

- Debe existir una ponderación entre los derechos constitucionales afectados y los bienes protegidos por el precedente.

- El juez debe motivar la decisión indicando el precedente que inaplica, exponiendo los fundamentos por los cuales se inaplica y la solución alternativa a la regulada en el precedente.

- $\quad$ Está prohibida la inaplicación tácita del precedente.

La inaplicación del precedente vinculante por el juez puede realizarse a través de los siguientes parámetros: La relevancia del precedente para resolver la controversia; el tipo de incompatibilidad existente entre el precedente y la Constitución: sea formal o de fondo; y, la última ratio en la decisión del juzgador en la inaplicación del precedente.

Finalmente, la decisión de inaplicar o apartarse del precedente vinculante tiene efectos interpartes, es decir, para el caso específico que conoce el juez.

\section{Bibliografía citada}

Alvarado Velloso, Adolfo (2011): Lecciones de Derecho Procesal Civil. Compendio del Libro: Sistema Procesal: Garantía de la Libertad adaptado al a Legislación procesal del Perú (Lima, EGACAL, Editorial San Marcos y Fundación para el Desarrollo de las Ciencias Jurídicas), Segunda Edición. 
Bernal Pulido, Carlos (2003): “La fuerza vinculante de la jurisprudencia en el orden jurídico colombiano", en Precedente, Revista Jurídica (Anuario 2013), pp. 1-43.

Castañeda Portocarrero, Fernando (2007): “Aproximación al Régimen Jurídico de la Independencia Judicial en el Perú", en AA.VV., Independencia Judicial - Visión y perspectivas (Lima, D\&L Publicaciones y Asociación de Jueces para la Justicia y Democracia, Lima), pp. 85-102.

Castillo Alva, José Luis (2008): “Los precedentes judiciales en materia penal como técnica de argumentación racional”, en: AA.VV., El precedente judicial y el precedente constitucional (Lima, Ara Editores), pp. 13-87.

García Toma, Víctor (2011): Constitución Política del Perú - Estudio Introductorio a la Constitución de 1993 (Lima, Gaceta Jurídica,) Primera Edición.

Gonzales Mantilla, Gorki (2007): “Las garantías para el desempeño profesional del Juez y la independencia judicial en un Estado Constitucional", en AA.VV., Independencia Judicial Visión y perspectivas (Lima, D\&L Publicaciones y Asociación de Jueces para la Justicia y Democracia, Lima), pp. 75-84.

Graziadei, Michele (2015): “Poder Judicial, sujeción del juez a la ley, y vinculación al precedente: una reflexión histórico comparativa sobre la justicia y sobre la garantía de los derechos", en AA.VV., Proceso y Constitución. El rol de las Altas Cortes y el derecho a la impugnación. Ponencias del Quinto Seminario Internacional de Derecho Procesal: Proceso y Constitución (Lima, Palestra), pp. 205-212.

Guerra Cerrón, Maria Elena (2007): “La Independencia Judicial: un derecho fundamental de los ciudadanos", en AA.VV., Independencia Judicial - Visión y perspectivas (Lima, D\&L Publicaciones y Asociación de Jueces para la Justicia y Democracia, Lima), pp. 49-68.

Hakansson-Nieto, Carlos: "Los Principios de Interpretación y precedentes vinculantes en la jurisprudencia del Tribunal Constitucional Peruano. Una aproximación", en Díkaion, (Vol. 23, № 18), pp. 55-77. 
Igartua Salaverría, Juan (2010): “La fuerza vinculante del precedente judicial”, en: AA.VV., Comentarios a los Precedentes Vinculantes del Tribunal Constitucional (Lima, Grijley), pp. 2540.

Indacochea Pevost, Úrsula (2010): “¿Por qué es obligatorio el precedente constitucional? Una aproximación a los fundamentos de su vinculatoriedad", en: AA.VV., Comentarios a los Precedentes Vinculantes del Tribunal Constitucional (Lima, Grijley), pp. 137-170.

Landa Arroyo, César (2010): “Los precedentes constitucionales”, en: AA.VV., Comentarios a los Precedentes Vinculantes del Tribunal Constitucional (Lima, Grijley), pp. 69-112.

López Flores, Luciano (2016): “Los “Poderes Judiciales”, proceso y política judicial: una mirada desde el Estado Constitucional", en Revista de la Maestría de Derecho Procesal de la Escuela de Postgrado de la Pontificia Universidad Católica del Perú (Vol. 6, № 2), pp. 147-178.

Lozano Tello, Jeanette (2011): “¿Hasta qué punto era necesario adaptar el precedente constitucional peruano a nuestra realidad jurídica?", en Actualidad Jurídica (Tomo 217, Diciembre 2011), pp. 177-183.

Marinoni, Luiz Guilherme (2013): Precedentes Obligatorios (Lima, Palestra).

Nogueira Alcalá, Humberto (2010): "La Sentencia constitucional en Chile: Aspectos fundamentales sobre su fuerza vinculante", en Estudios Constitucionales, Revista Semestral del Centro de Estudios Constitucionales (Año 4, № 01), pp. 79-115.

Núñez Santamaría, Diego (2012), "Ideas para una Corte Constitucional como garante de derechos fundamentales. La Corte Constitucional, status, legitimidad y Corte de Precedente", [Disponible en: https://bit.ly/2RjIhZa].

Pásara, Luis (2007): "La Independencia judicial: una reconsideración”, en AA.VV., Independencia Judicial - Visión y perspectivas (Lima, D\&L Publicaciones y Asociación de Jueces para la Justicia y Democracia, Lima), pp. 103-104.

Superti, Héctor Carlos (2006): “La Garantía Constitucional del Juez Imparcial en materia penal”, en AA.VV, El Debido Proceso (Buenos Aires, Ediar), pp. 313-363. 
Velezmoro, Fernando (2010): “El precedente constitucional según la jurisprudencia del Tribunal Constitucional peruano y el neoconstitucionalismo". en: AA.VV., Comentarios a los Precedentes Vinculantes del Tribunal Constitucional (Lima, Grijley), pp. 113-136.

Vinatea Medina, Ricardo: “La aplicación del precedente vinculante del Tribunal Constitucional Peruano a la jurisprudencia nacional”, [fecha de consulta: 20 de mayo del 2012] [Disponible en: https://bit.ly/3cMV65P].

Zúñiga Urbina, Francisco (2006): “Sentencias del Tribunal Constitucional y Poder Judicial. El valor del precedente", en Estudios Constitucionales (Año 4, № 01), pp. 151-172.

\section{Normas jurídicas citadas}

Resolución Administrativa $N^{\circ}$ 095-2004-P-TC, Reglamento Normativo del Tribunal Constitucional peruano, 14 de septiembre del 2004

Resolución OCMA N 021-2006/PJ, Disponen que todos los órganos jurisdiccionales de la República den cumplimiento a precedentes vinculantes señalados por el Tribunal Constitucional sobre criterios de procedibilidad en demandas de amparo en materia laboral y sobre impuesto a la importación de los juegos de casino y máquinas tragamonedas, Diario Oficial “El Peruano”, 04 de abril del 2006.

Ley N²28237, Código Procesal Constitucional Peruano, Diario Oficial “El Peruano”, 31 de mayo del 2004.

\section{Jurisprudencia citada}

\section{Jurisprudencia de Colombia:}

Corte Constitucional Colombia: Jesús Echeandía Sánchez contra Fiscalía General de la Nación, el Juzgado Penal Especializado del Circuito de Manizales y la Sala Penal del Tribunal Superior de Manizales (acción de tutela), de 27 de septiembre del 2001 Expediente T-1031/01. [Disponible en: https://bit.ly/35pwLyN]. 
Corte Constitucional Colombia: Luis Daniel Montero Piraquive contra Sala Laboral del Tribunal Superior de Bogotá (acción de tutela), de 04 de febrero del 2010 Expediente T-2364128 [Disponible en: https://bit.ly/2S99U7v].

Corte Constitucional Colombia: Demanda de inconstitucionalidad contra el artículo 10 (parcial) de la Ley 1437 de 2011 "por la cual se expide el Código de Procedimiento Administrativo y de lo Contencioso Administrativo", 24 de agosto del 2011, Expediente D-8413 [Disponible en: https://bit.ly/3ic3X4i].

Corte Constitucional Colombia: Demanda de inconstitucionalidad contra el artículo 102 (parcial) de la Ley 1437 de 2011, por la cual se expide el Código de Procedimiento Administrativo y de lo Contencioso Administrativo, de 01 de noviembre del 2011, Expediente D-8473. Sentencia C-816/11 [Disponible en: https://bit.ly/3wS5r7Z].

\section{Jurisprudencia de Bolivia:}

Tribunal Constitucional Plurinacional: Autoridad Remitente: Marlenne Pino de Terán y Renán Jiménez Sempértegui, Vocales de la Sala Penal Tercera de la Corte Superior del Distrito Judicial de Cochabamba (a instancia de Fernando Reque Humberto Cáceres Pacheco) (Recurso Indirecto o Incidental de Inconstitucionalidad), de 08 de julio del 2002, Expediente 200204478-09-RII. Sentencia 058/2002.

Tribunal Constitucional Plurinacional: Servicios Aeropuestos Bolivianos Sociedad Anónima (SABSA) contra Ramiro Claros Rojas, Edgar Terrazas Melgar y Oswaldo Céspedes Céspedes (Recurso de Amparo), 16 de noviembre del 2004. Expediente 2004-09677-20-RAC. Sentencia 1781/2004-R.

Tribunal Constitucional Plurinacional: Revisión de Resolución 35/2004 de la Sala Civil, Familiar y Comercial de la Corte Superior del Distrito Judicial de Oruro, de 05 de julio del 2005. Expediente 2004-10528-22-RAC. Sentencia 0753/2005-R.

\section{Jurisprudencia de Chile:}

Tribunal Constitucional Chile: Recurso de Control de Constitucionalidad respecto del Proyecto de Ley que crea Juzgados de Policía Local en las comunas que indica, Rol N 171-1993 , 22 de julio de 1993. 


\section{Jurisprudencia de Venezuela:}

Tribunal Supremo de Justicia de Venezuela: Acción de Interpretación Constitucional, respecto al alcance, interpretación uniforme y aplicación de las normas contenidas en los artículos 57 y 58 de la Carta Magna, referidos a los derechos a la libre expresión, a la información, de réplica y de rectificación, Sala Constitucional, de 19 de julio del 2001. Expediente 01-1362. Sentencia 1309 [Disponible en: https://bit.ly/3wTQ0B2].

\section{Jurisprudencia del Tribunal Constitucional Peruano:}

Miguel Cabrera León contra el Sindicato Unitario de Trabajadores Municipales del Rímac (Proceso de Amparo), Expediente 1042-2002-AA/TC , de 06 de diciembre del 2002.

Municipalidad Distrital de Lurín contra la Municipalidad Provincial de Huarochirí y la Municipalidad Distrital de Santo Domingo de Los Olleros (Proceso de Inconstitucionalidad), Expediente 0024-2003-AI/TC, de 10 de octubre del 2005.

Fiscal de la Nación contra el Congreso de la República (Proceso de Inconstitucionalidad, Expediente 0004-2006-PI/TC, 29 de marzo del 2006.

Poder Ejecutivo (Ministerio de Comercio Exterior y Turismo) contra el Poder Judicial (Proceso Competencial), Expediente 006-2006-PC/TC, de 13 de febrero del 2007.

Dirección Regional de Pesquería de la Libertad contra los Magistrados de la Segunda Sala Civil de la Corte Superior de Justicia de Trujillo (Proceso de Amparo). Expediente 4853-2004PA/TC, 19 de abril del 2007.

Transportes Vicente, Eusebio, Andrea S.A.C. - Transportes VEA S.A.C. contra el Ministerio de Transportes y Comunicaciones (Proceso de Amparo), Expediente 05961-2009-PA/TC, de 04 de junio del 2010.

Ministerio de Transportes y Comunicaciones (MTC) en representación del Presidente de la República contra el Poder Judicial (Proceso Competencial), Expediente 00001-2010-CC/TC, de 12 de agosto del 2010. 
Grela Eufemia Felipe de Alcalde contra la Oficina de Normalización Previsional (ONP); “Grela Eufemia Felipe de Alcalde (Proceso de Amparo), Expediente 005525-2011-PA/TC, de 19 de abril del 2011.

Jesús Giles Alipazaga y otros contra la Fiscal de la Cuarta Fiscalía Provincial Penal Corporativa de Huánuco y otros (Proceso de Amparo), Expediente 00512-2013-PHC/TC, 19 de junio del 2013.

José María Gómez Távares y otros c/. Marco Antonio Guerrero Castillo y otros - Jueces de la Sala Penal de Apelaciones de Piura (Proceso de Amparo), Expediente 03950-2012-PA/TC, 28 de marzo del 2014.

Alberto Fujimori Fujimori contra los jueces que integraban la Sala Penal Especial de la Corte Suprema de Justicia de la República (Proceso de Amparo), Expediente 01460-2016-PHC/TC, 03 de mayo del 2016.

\section{Jurisprudencia del Poder Judicial Peruano:}

Sala Civil de la Corte Superior de Justicia de Tacna: Kanagawa Corporation S.A.C. contra la Superintendencia Nacional de Administración Tributaria - SUNAT y otros 24 (Proceso de Amparo), Expediente 00961-2009-0-2301-JR-CI-01, de septiembre del 2010.

Juzgado Mixto Permanente del Módulo Básico de Justicia de la Esperanza: Nelson Jubenal Flores Ayllón contra Proyecto Especial Chavimochic y otro (Pago de Beneficios Sociales) Expediente 00058-2014-0-1618-JM-LA-01, de 24 de julio del 2015.

Cuarta Sala Laboral Permanente de Lima (Tribunal Unipersonal): Ruth Madeleyne Vilca Vilca contra el Poder Judicial (Desnaturalización de contrato y otro), Expediente 27013-2013-01801-JR-LA-03, 17 de julio del 2015.

\section{Resolución del Ministerio Público Peruano (Fiscalía de la Nación):}

Fiscalía de la Nación: Fernando Antonio Galarreta Paredes por Fiscalía Suprema de Control Interno (Denuncia Penal por prevaricato y abuso de autoridad), Expediente 380-2007CAJAMARCA, 8 de enero del 2010. 